\title{
Da Disciplina à Transdisciplinaridade pela Transgressão Waratiana: uma releitura heideggeriana do ensino jurídico ${ }^{1}$
}

\section{From Discipline to Interdisciplinarity in Luis Alberto Warat's Perspective: a heideggerian re-reading of law studies}

\author{
Albano Marcos Bastos Pêpe \\ Daniela Boito Maurmann Hidalgo
}

\begin{abstract}
Resumo: O presente artigo se propõe a repensar a questão da educação em uma perspectiva transformadora e libertadora, em direção à superação da relação sujeito-objeto que impera no modo de fazer educação na modernidade. A era da técnica e o paradigma racionalista pensaram a educação a partir da disciplina. A proposta que se apresenta confia na superação da era do dispositivo (Ge-Stell), na qual a educação é um produto cuja aquisição permite o acoplamento do instrumento: o diploma, cuja função é alterar a essência das coisas. Busca-se refletir a educação a partir de um novo paradigma: da vivência e da transdisciplinaridade, em que, pelo caminho da fala waratiana, a relação sujeito-objeto dá lugar à intersubjetividade e ao reconhecimento do outro.
\end{abstract}

Palavras-chave: Educação. Disciplina. Transdisciplinaridade. Solipsismo. Intersubjetividade.
Abstract: The present article aims at rethinking the educational issue through a transforming and liberating perspective, in order to surpass the relation, S-O (subject-object) which governs the way of making education in the modernity. The technology era and the rationalist paradigm thought education from the discipline- based approach. The present proposal believes in the suppression of of Ge-Stell era (era of enframing) that sees education as a product, which the acquisition allows the coupling of the instrument, the diploma, whose function is to alter the essence of things. We intend to contemplate education from a new paradigm: the transdisciplinary experience in Warat's discourse, the S-O relation gives place to the intersubjectivity and to the recognition of the other.

Keywords: Education. Discipline. Transdisciplinarity. Solipscism. Intersubjectivity.

1 Recebido em: 23/08/2012.

Revisado em: 08/11/2012.

Aprovado em: 24/02/2013. 


\section{Introdução}

O presente ensaio pretende propor uma reflexão acerca dos rumos que o ensino jurídico tem tomado nessa quadra da história, traçando o perfil das (im)possibilidades de uma retomada de um ensino transformador. Para essa empreitada, se projeta uma releitura, a partir da filosofia hermenêutica e da hermenêutica filosófica, daquilo que ousamos chamar de transgressão Waratiana.

Propõe-se uma virada da disciplina à transdisciplinaridade. A disciplina, entendida como modo de dominação dos corpos e das mentes, e ligada, no ensino jurídico, à dogmática, desprendida da realidade social e sem compromisso com sua real afirmação como conhecimento a ser compreendido, interpretado e aplicado no mundo prático - no qual os valores constitucionais são desprezados, os conflitos se tornam mais complexos, as promessas do Estado Constitucional resultam descumpridas -, encontra suas impossibilidades pelo aprisionamento da educação na esfera burocrática e irrefletida da era da técnica. Já a transdisciplinaridade é entendida como um lócus privilegiado no seio da qual os saberes se encontram em uma significação no mundo, projeto de um mundo a ser sempre transformado com a construção de sentidos autênticos que, no Direito, exige que o ensino jurídico volte o seu olhar à sua capacidade de transformação. Transformação para projetar, no mundo prático, uma transformação social de respeito aos valores comunitários, de solução de conflitos, e não seu acirramento, de cumprimento de promessas, numa microrrevolução a partir de nós mesmos, atores do processo/projeto educacional.

O necessário, então, o enfrentamento do que precisa ser desvelado, a abertura para o novo, é o que se projeta aqui, num encontro-desvelamento-acontecimento, a partir de Heidegger, com Warat.

\section{A Era da Técnica como Princípio Epocal e a Viragem da Vida Ativa ao Homofaber e ao Animal Laborans}

A era da técnica é a era do método e do disciplinamento, em que tudo se converte em valor de troca. A experiência vivida, no mundo, como 
linguagem, é subtraída, a própria experiência mundana é subtraída e substituída pela adequação a um fim. Só tem lugar o que for adequado a uma utilidade específica. A reflexão, a crítica e todas as noções que exigem a convivência efetiva, ser-com-os-outros, como a justiça, a solidariedade e o direito, são reduzidos a utilidades. É a técnica que substitui o ser.

\subsection{A Era da Técnica}

A educação na era da técnica é a educação do método e do disciplinamento, da formação de mentes acríticas, construídas para a afirmação desses métodos capazes de levar à verdade. É preciso, então, começar por desvelar o que está na base da afirmação de Warat de que a era atual é a era do "[...] paradigma da distinção, do dever e do método, tão caracterizador das funções totalizantes das ciências sociais" (2000, p. 140). Trata-se da necessidade de investigar o domínio da técnica à qual se acham submetidas as possibilidades de sentido, porque "[...] numa civilização técnica, é inevitável que não se premie, tanto a potência criadora do indivíduo, como o seu poder de adaptação" (GADAMER, 1983, p. 44). Essa constatação apresenta significação evidente quando se reflete sobre a questão do ensino. O indivíduo solipsista, confiante em sua racionalidade autossuficiente, é o mesmo indivíduo que assume, na era da técnica, o papel de reprodutor de sentidos universalizados e indiscutidos. É o sujeito que emerge apoiado sobre duas metafísicas: o racionalismo e o realismo, e que fundamenta o conhecimento epistemológico como abstração e confina a experiência, em seu sentido autêntico, de vivência, na inautenticidade do experimento científico.

Como afirma Agamben (2005, p. 25):

Em um certo sentido, a expropriação da experiência estava "implícita" no projeto fundamental da ciência moderna. [...] a ciência moderna nasce de uma desconfiança sem precedentes em relação é experiência como era tradicionalmente entendida.

A morte da experiência, substituída pelo método, procura vencer a insegurança do mundo e, para isso, busca certezas pré-moldadas e capazes de minimizar os riscos de uma sociedade em contínua mutação. Mira- 
gem de segurança em um deserto de sentidos, no qual apenas a aparência tem um lugar definido.

Essa realidade, consumada na era da técnica, em que o dispositivo é o último princípio epocal anunciado por Heidegger $(2006 a)^{2}$, é a realidade em que o sujeito da modernidade dá lugar ao mundo no qual não só as coisas são produto da fabricação, mas também os próprios homens são o produto acabado da técnica. Época de "[...] 'debilidade' do ser [...]" (VATTIMO, 2002, p. 14) e época do disciplinamento dos saberes e das mentes.

A era da técnica é a era da disciplina. Como afirmado por Foucault, a disciplina é instrumento da técnica, mas um instrumento com um novo sentido, uma nova missão. Originalmente, cabia às disciplinas,

[...] principalmente, neutralizar os perigos, fixar as populações inúteis ou agitadas, evitar os inconvenientes de reuniões muito numerosas; agora se lhes atribui (pois se tornaram capazes disso) o papel positivo de aumentar a utilidade possível dos indivíduos. (FOUCAULT, 2000, p. 173)

Na era da técnica, tudo é calculado e medido em termos de utilidade. Indivíduos úteis aos mecanismos reprodutivos do mercado e do consumo. O saber atende aos anseios do poder disciplinador quando vela, esconde, as relações de poder e, com isso, o faz mais presente e mais forte, pois:

Quando tiverdes conseguido formar assim a cadeia das idéias na cabeça de vossos cidadãos, podereis então vos gabar de conduzi-los e de ser seus senhores. Um déspota imbecil pode coagir escravos com correntes de ferro; mas um verdadeiro político os amarra bem mais fortemente com a corrente de suas próprias idéias [...]; o desespero e o tempo roem laços de ferro e aço, mas são impotentes contra a união habitual das idéias, apenas conseguem estreitá-la ainda mais; e sobre as fibras moles do cérebro funda-se a base ina-

2 Relevante notar que Heidegger tratou diretamente a questão relativa ao último princípio epocal - o Ge-Stell - em quatro conferências intituladas "A Coisa", "O Dispositivo", "O perigo" e "A Viravolta". 
balável dos mais sólidos impérios. (SERVAN apud FOUCAULT, 2000, p. 86)

\subsection{A Função da Disciplina}

$\mathrm{Na}$ educação, esses modos simbólicos de dominação encontram-se à mão e, ao mesmo tempo — talvez por isso mesmo — seu sentido encontra-se velado. A familiaridade de expressões ambivalentes, tomadas como um sentido em si, único, impede a visão do que está mais próximo.

Para quem usa óculos, por exemplo, que, do ponto de vista do intervalo, estão tão próximos que os 'trazemos no nariz', esse instrumento de uso, do ponto de vista do mundo circundante, acha-se mais distante do que o quadro pendurado na parede em frente. Esse instrumento é tão pouco próximo que, muitas vezes, nem pode ser encontrado imediatamente. (HEIDEGGER, 2006b, p. 161)

Com efeito, o que é mais familiar e está imediatamente à mão é aquilo que usamos, falamos, sem a atenção questionadora. É o que se dá com a disciplina, usada, todos os dias, para designar os saberes a serem estudados, vela o seu sentido de violência simbólica, cuja eficácia advém, justamente, desse (a)tencionamento a respeito de seu sentido. Como lembra Paviani (2005):

Nesse sentido, o termo disciplina, usado nos currículos, esconde em suas origens semânticas, um sentido de norma, de punição, de formação intelectual, emocional e física. O conceito de disciplina traz marcas que ultrapassam o puro ensinar ou aprender, contém a idéia ou a ação de disciplinar, isto é, de sujeitar o discípulo a receber ensino de alguém, de 'aprender' certos conteúdos, memorizar noções, definições, datas, nomes, teses, teoremas. (PAVIANI, 2005, p. 28)

A escola, como os quartéis e as fábricas, segundo Michel Foucault, funciona como instrumento da mecânica do poder disciplinador. A disciplina, produzida por meio dessas instituições, segrega as mentes, 
[...] fabrica assim corpos submissos e exercitados, corpos 'dóceis'. A disciplina aumenta as forças do corpo (em termos econômicos de utilidade) e diminui essas mesmas forças (em termos políticos de obediência). (FOUCAULT, 2000, p. 119)

Essa disciplina da era da técnica é a disciplina que se observa em salas de aula, na relação provocada entre professor e alunos, em que não há intersubjetividade, não há troca, apenas um ritual destinado a conferir àquele que aprende a técnica que ele mesmo julga necessária e suficiente para haver-se com o mundo, porque o que ele precisa é que lhes sejam dadas as respostas existentes para o enfrentamento da representação que ele tem do mundo.

Compreende-se, com isso, que o indivíduo, destituído de sua dimensão com-os-outros, massificado por sua dimensão de consumidor e identificado por essa condição, é reproduzido por uma disciplina que se impõe como violência simbólica necessária à manutenção da ordem de um mercado no qual inclusive o ensino é tomado como produto, destinado a um consumidor que "sabe o que quer", porque é condicionado a acreditar que sua razão é autossuficiente. O que esse indivíduo quer é um ensino que reproduza fórmulas de acesso (fictício) a um mercado que estaria (também ficticiamente) de portas abertas para seus anseios.

Nesse ritual que encobre sentidos: a oferta de educação, em todos os níveis e, especialmente, em nível superior, cumpre-se uma função na era da técnica. Trata-se de fabricar utilidades, indivíduos; na exata acepção do termo, mônadas solitárias incapazes de reconhecimento comum, reduzidas ao valor de troca cuja procura é subsumida na obtenção do dispositivo necessário à sua admissão em um universo fictício, admissão que lhes é dada como meta a ser alcançada. Alcançada a meta, isto é, acoplado esse dispositivo, que, na realidade do ensino, mostrou-se ser o "Diploma" ou o "Certificado de Conclusão", ou, no Direito, a "Inscrição na Ordem dos Advogados do Brasil”, não há nada mais a buscar. Não há saberes, não há compreensão, não há questionamentos. Há apenas a realidade de que aquele dispositivo lhes concederá o acesso a uma condição que, ao mostrar-se como fictícia, nem mesmo assim leva ao questionamento autêntico do sistema, pois a responsabilidade pela ineficácia do dispositivo 
é sempre de uma esfera mais ampla: a economia, o mercado, o Governo. Trata-se do resultado de um disciplinamento bem-sucedido.

Esse disciplinamento cumpre a função da inversão da dimensão da fala e do compartilhar em direção ao homo faber e ao animal laborans, que, em sua dimensão instrumental e prosaica, superdimensionam a sua utilidade, inviabilizando a construção de um mundo comum. Nessa realidade, a educação, de possibilidade de construção de mundo e de transformação social, se converte em produto e em reprodução de sentidos e fabricação de mentes. Isso porque o lugar da crítica, na era da técnica e da massificação provocada por ela, é um lugar marginal.

\section{A Relação Sujeito-Objeto e a Ambivalência do Limite}

A relação sujeito-objeto tende ao encobrimento do ser, para que somente o ente se faça presente, e é isso que impede a realização dos sentidos e permite as vozes unívocas atemporais, universalizantes de sentidos. É a condição de possibilidade do homem como ente a ser fabrilmente moldado e transformado em sua essência.

Essa transformação da essência das coisas é veiculada por modos previamente dados de acesso ao ente — os princípios epocais - que provocam o esquecimento do ser desse ente. Esse encobrimento, desde a ideia em Platão até o dispositivo, na era da técnica, é um erro, porque a compreensão do mundo a partir do dispositivo, em relações de instrumentalidade, observa o mundo e a natureza como algo que pode ser transformado. Essa é a relação do homem com o mundo na era da técnica, o século XX, em que tudo é meio, inclusive ele, o homem, cuja essência, no sentido do que ele é, deve estar apta a ser transformada. A essência das coisas não reflete o seu ser, o que "são" são meros reflexos da transformação do ser dos entes que ocorre com a sua entificação, com a atribuição de um único sentido, dado, familiar, impensado, não discutido, deixando a essência desses seres velada, o que "aparece" é o que é a essência das coisas. O sujeito solipsista da era da técnica transmuta o mundo em representações, capas de sentido destinadas ao encobrimento desses seres. Com a educação, e o papel, primordial, que ocupa, ou deveria ocupar, não 
é diferente. Sua essência, transformadora de mundo é moldada e aparece como reprodutora de mundo. Como ilustração dessa realidade, impõe-se a imagem de Martin Heidegger (2006a, p. 20):

[...] o próprio Reno aparece, como um dispositivo. A usina hidroelétrica não está instalada no Reno, como a velha ponte de madeira que, durante séculos, ligava uma margem à outra. A situação se inverteu. Agora é o rio que está instalado na usina. O rio que hoje é Reno o é pela essência da usina.

A técnica como um encontro provocado com o ente, como um modo de interpretação representativa do mundo, em que sujeito e objeto se opõem em uma relação significativa artificialmente construída, serve como instrumento, como "Ge-Stell" (dis-positivo) que domina a natureza e provoca sua alteração. Essa técnica dominadora, que é o ensino pensado pelas mentes do racionalismo, altera a essência da educação, de modo a fazer dela o oposto do que ela é: mera substância a ser acoplada. "Enquanto representarmos a técnica, como um instrumento, ficaremos presos à vontade de dominá-la. Todo nosso empenho passará por fora da essência da técnica". (HEIDEGGER, 2006a, p. 11)3

Trata-se de uma transformação inumana, artificial, tendente a realizar as necessidades também artificiais de um mundo presentificado como espaço de fabricação e de consumo, não de relações humanas. $\mathrm{O}$ espaço humano é transformado de espaço de relações entre os homens para espaço de fabricação de coisas e necessidades para esses homens. A dimensão do humano deixa de ser a palavra, a relação sintática e semântica com o outro, para ser o espaço do homo faber. Desaparece o propriamente humano para que a técnica apareça. A situação se inverteu, o homem não busca sua formação, como indivíduo, como comunidade, ele procura um dispositivo que altere sua essência, não no sentido que ele é. O diploma não é mais o resultado de uma caminhada, formadora, transformadora. É apenas uma prótese - o dispositivo, Ge-Stell — instalada no homem, sem transformá-lo, sem abrir-lhe os olhos, ao contrário, destinada a fe-

${ }^{3}$ Segundo Heidegger (2006a, p. 11), “[...] a essência de alguma coisa é aquilo que ela é. Questionar a técnica significa, portanto, perguntar o que ela é". 
char-lhe os olhos, destinada a impedir-lhe o acesso às condições de possibilidade de questionar. Conforme dissera Immanuel Wallerstein, não há "[...] saída dentro da estrutura do sistema histórico existente" (WALLERSTEIN, 2002 apud SILVA, 2004, p. 297), já que, consoante completa Ovídio Araújo Baptista da Silva, podemos "[...] desfrutar da sensação de liberdade, na mais absoluta plenitude. Liberdade para concordar, pela inocuidade das divergências, ou do próprio questionamento do sistema". (SILVA, 2004, p. 297)

Essa visão de mundo, em que tudo é destinado à transformação fabril, traz consigo o perigo, sempre presente e atuante, e sempre realizado, desse mau uso da técnica, e a dimensão de sentido em que se pode superar essa modernidade técnica é a viravolta proposta por Heidegger (2006b, p. 68), um retorno à dimensão do ser, que se dá no mundo que é linguagem, a partir do "fenômeno" como o que se revela, "[...] o que se mostra em si mesmo [...]", e não como aparência.

Enfrentar, desvelar os sentidos inautênticos da era da técnica, desconstruindo o sujeito solipsista e a absoluta ausência de vínculos de que padece, pois, é pressuposto para repensar, ou melhor, construir a dimensão ética. Ambas as dimensões - a virada em direção à fenomenologia existencial e o reconhecimento do Outro como dignidade e como condição de possibilidade do exercício dos direitos e limite desse mesmo exercício, enquanto responsabilidade - são imprescindíveis para superação da era da técnica e de sua respectiva visão do mundo em direção à virada do pensar a dimensão do homem como ser humano. Uma é pressuposto da outra.

Esse caminho desvelado do que ela representa até a possível virada em direção a uma superação desobjetificante do mundo é, então, o ser cuja essência precisa ser desvelada. Segundo Vattimo (2002, p. 178-179), “[...] o Ge-Stell, o mundo da técnica, não é apenas aquele em que a metafísica alcança seu ponto culminante e seu mais elevado e completo desenvolvimento, mas também, e por isso mesmo, 'um primeiro lampejar do Ereignis" ". 


\section{Proposta Pedagógica ou Eterno Refazer de Possibilidades?}

Tratar da questão da educação, buscando a superação de seus limites de possibilidade para o futuro, exige o novo, o desviante, uma dose de subversão. Impossível, por isso, deixar de pensar em Warat e sua conhecida afirmação de que não se prepara a aula. Essa afirmação, tão surpreendente - para quem não está ocupado em pensar novos rumos para a educação, numa perspectiva desveladora de sentidos - quanto questionadora, embora enunciada como afirmação, convida ao questionamento das bases da epistemologia tradicional e, mais profundamente, convida a "[...] descobrir o sentido onde, muito provavelmente, segundo todos os indicativos de uma totalidade de sentido, ele não se encontrará". (SOUZA, 2000, p. 165)

Como afirma Heidegger (2006a, p. 40): “A busca ciente pode transformar-se em 'investigação' se o que se questiona for determinado de maneira libertadora". Como dito por Warat, lembrando Barthes, o lugar mais sombrio situa-se sempre sob a lâmpada. (WARAT, 2000, p. 38)

Não é por outro motivo que a reflexão sobre o estágio da educação e suas perspectivas, ou sobre o que se pode pensar, o que se deve fazer, em relação àquele que, para Kant (2002, p. 20), “[...] é o maior e o mais árduo problema que pode ser proposto aos homens [...]" — a educação depende do necessário desvelamento dos sentidos encobertos na estrutura educacional em direção à autenticidade de uma compreensão do homem como projeto, e não como dado, realidade acabada.

O ensino jurídico, como serviço prestado no mercado de consumo, é o que precisa ser objeto de reflexão. Nessa quadra da história, o modelo de ensino confia no sequenciamento do método, em que professores e alunos têm uma pauta a seguir, em direção a um destino que é sempre o mesmo: a conclusão do curso. O ensino não é transformador. Sequer se busca, seriamente, a capacidade efetiva de transformação de mundo a partir do ensino. As instituições, que seguem abertamente filosofias mercadológicas estranhas ao universo educacional, se contentam em pautar o ensino dogmático como norte de seu trabalho. A pauta, todavia, sequer é adequadamente cumprida, pois a compreensão da dogmática fica a meio caminho do necessário para o efetivo aprendizado dogmático. Os dados 
relacionados às reprovações maciças em concursos públicos e na prova da Ordem dos Advogados do Brasil, tão conhecidos no universo jurídico e fora dele, testemunham essa realidade. Sequer formamos pessoas adequadamente instrumentalizadas na dogmática jurídica ${ }^{4}$.

Não há transformação possível em um mundo em que sequer o saber dogmático, conhecido receptor de ideologias e consagrador de posições de poder, é suficiente. Essa insuficiência não apenas permite, mas legitima o senso comum teórico, impedindo o acontecimento de um sentido transformador do Direito. Essa realidade se projeta da práxis jurídica (Poder Judiciário e seus vários atores) ao ensino jurídico, e, deste, à práxis, em um círculo vicioso que impede o acontecer dos sentidos que o Direito pode projetar na sociedade, como motor de transformação social em prol das promessas do novo modelo de Estado transformador que ainda se pode ler na Constituição Federal de 1988.

O ensino jurídico da atualidade, é o que no presente trabalho se afirma, sequer oferece o ensino dogmático, contentando-se com a relação sujeito-objeto (S-O), em que o ser é objetificado pelo ente. Um acoplamento de sentidos, à maneira da metafísica clássica, em que o objeto desejado - o diploma - com sua essência de sentido pré-constituída, acopla-se ao sujeito, modificando sua essência. $\mathrm{O}$ sujeito bacharel que vale pelo título, não por sua capacidade de atuação ou transformação.

Uma visão autêntica da educação em oposição ao nihilismo, esse é o desiderato da reflexão a que se propõe o presente trabalho. O diploma não tem, nem se pode nele admitir, um sentido em si, seu significado deve ser o resultado de um projeto transformador do sujeito, transformação que

\footnotetext{
${ }^{4}$ Segundo Warat (1995), "Em seu processo histórico, a dogmática tradicional aponta três etapas de aplicação de seu método técnico-jurídico. A primeira etapa compreende a época da conceitualização dos testos legais. Esta se baseia no pressuposto de que não há mais direito que o ordenamento jurídico estabelecido através das leis validamente ditadas e vigentes [...]. A segunda etapa é propriamente a da dogmatização jurídica, da fixação dos dogmas jurídicos, da elaboração das preposiçõeså, categorias e princípios obtidos a partir de conceitos jurídicos, extraídos dos textos legais [...]. Finalmente entramos na terceira etapa da dogmática jurídica que se caracteriza pela sistematização, chegando assim à meta perseguida pela ciência de matriz positivista, que é a constituição de uma disciplina específica, objeto de conhecimento, em um sistema." (WARAT, 1995, 17-19)
} 
se projeta na sociedade. A educação deve ser transformadora. Do contrário, é vazia de sentido.

A transgressão Waratiana, em uma leitura heideggeriana de retorno ao mundo vivido, em oposição aos conceitos e acoplamentos instrumentais da modernidade, segundo o pensamento ora esposado, é a forma de superação da expropriação da experiência em direção a um trajeto, sempre renovado e reconstruído, da educação como acontecimento, em que o sujeito crepuscular bachelardiano (PEPE, 2007, p. 40) - o homem do dia, da ciência, e o homem da noite, o poeta, ou os personagens de Jorge Amado e também de Warat (2000, p. 23), Teodoro e Vadinho — enfim, o apolínico e o dionisíaco, representem metáforas contrapostas à ideologia da castração, de que fala a obra waratiana. Tal necessidade emerge do reconhecimento de que: "O poder simbólico [...] só se exerce se for reconhecido, quer dizer, ignorado como arbitrário”. (BOURDIEU, 2005, p. 14)

Desvelar os sentidos impensados, encobertos, acerca do discurso educacional, que instaura uma relação assujeitadora-objetificadora entre professor e aluno, sujeito e objeto, é, necessariamente, o caminho a ser trilhado em prol da construção da educação como superação do paradigma representacional do indivíduo solipsista, desarraigado do mundo, desvinculado dos outros, incapaz de assumir qualquer responsabilidade que não sejam seus interesses, incapaz de construir um mundo comum.

Warat (2000, p. 140), em sua genialidade, disse que

[...] a carnavalização instaura um clima compreensivo para — lembrando algumas coisas do romantismo - recuperar a espontaneidade e neutralizar a suprema racionalidade dos quadros de referência que, antecedendo-a, amarram a vida.

Como compreender essa afirmação? O que ela propõe rumo ao despertar do novo? O que se anuncia para além da subjetividade da ontologia da tradição e para a objetificação do sentido do ensino na era da técnica?

A aula e o ensino estão sendo pensados pela técnica. Dogmatizados como o possível apenas por meio da mesma fórmula instrumental, com 
conteúdo determinado que deve ser apresentado e absorvido sob a fórmula de uma aula, não no sentido bartheano, de saber e de sabor (BARTHES, 1978 , p. 21), mas como um instrumento em que os passos, as programações em tópicos, levarão a um resultado dado a priori. Cada aula deve ser suficiente para apresentar determinado número de tópicos. O aluno recebe o conteúdo sem um questionamento. Pensa apenas que aquele conteúdo é a técnica necessária para uma determinada tarefa e deve ser absorvida para que a tarefa seja completada. A tarefa é sua transformação em técnico. Esse questionamento, condição de possibilidade da interação, ao faltar, transmuta o ensino em algo que ele não é, a técnica o transforma.

O ensino deixa de ser o limite de sentido. Imperioso lembrar que, aqui, a expressão sentido é utilizada a partir da analítica do Dasein. Em Heidegger, o limite, a finitude, é a dimensão da possibilidade, a partir dele se constrói a possibilidade. "O limite não é aquilo onde algo deixa de ser, mas como os gregos o reconheceram, o limite é aquilo a partir de onde algo começa o desdobramento de seu ser" (STEIN, 2001, p. 124). O ensino passa a ser o limite mesmo, no sentido moderno e corrente da expressão, o fim das possibilidades que se anunciavam.

Para a viravolta na questão do ensino, há necessidade de se tomar consciência da impossibilidade de construção de um novo paradigma, de um novo método para a formatação da aula, do encontro entre professor e aluno. A técnica e o instrumento - a disciplina — substituídos pela vivência e pela transdisciplinaridade. O que é isso? A possibilidade de tomada de consciência de que a educação não pode ser um encontro provocado, algo disciplinado, formatado e apresentado como um dado, uma fase a ser cumprida na vida de ambos - professor e aluno - , mas que o encontro seja como um acontecimento, no qual os saberes sejam vivenciados, saboreados, como diria Barthes, e o não disciplinado esteja presente, porque "[...] o que pode ser opressivo num ensino não é finalmente o saber ou a cultura que ele veicula, são as formas discursivas através das quais ele é proposto”. (BARTHES, 1978, p. 43)

A partir dessa ideia, a conclusão só pode ser a de que, quando se discute educação, não se pode pretender encontrar uma fórmula, o que fazer é o que se descobrirá a cada novo encontro, em que uma nova proposta de 
discussão é feita e vivenciada. Não há a solução esperada e investigada. $\mathrm{O}$ saber precisa ser construído em uma relação entre os atores — professor e aluno - na qual aprendam ambos a pensar o novo, compreendendo-se e compreendendo os outros. Haverá, assim, uma possibilidade de vivenciar o momento do saber, sobre o que falam, por exemplo, os textos. Essa dimensão é encontrada em Gadamer (1983, p. 358):

[...] se ouve alguém ou quando se empreende uma leitura, não é necessário que se esqueçam todas as opiniões prévias sobre seu conteúdo e todas as opiniões próprias. O que se exige é simplesmente a abertura para a opinião do outro ou para a opinião do texto. [...] Em princípio, quem quer compreender um texto, deve estar disposto a deixar que este lhe diga alguma coisa. Por isso, uma consciência formada hermeneuticamente deve, desde o princípio, mostrar-se receptiva à alteridade do texto.

É preciso compreender essa afirmação no sentido de seu reconhecimento da imprescindibilidade da dimensão da alteridade, no reconhecimento e respeito pelo valor do Outro não apenas na perspectiva da interpretação de textos, mas na totalidade da interpretação, que já é compreensão, do mundo, na relação do homem com as coisas, com os outros, o que inclui a opinião do Outro, a disponibilidade de ouvi-lo, de se comunicar com ele, com os textos. Para o ensino, a importância desse reconhecimento é radical, não como discurso fabricado para manutenção do paradigma objetificador/assujeitador com o qual se está acostumado. Essa dimensão é imprescindível na construção do saber entre professor e aluno, pois ambos precisam aprender a dialogar, a formar uma visão crítica, a respeitar a opinião do Outro, o que pressupõe reconhecê-lo, viabilizando a construção de noções comunitárias como solidariedade, justiça, comunidade, comunicação. Não mais apenas dimensões individuais, mas também não coletivas - mero somatório de individualidades.

A aula como encontro de um acontecer produtivo, de vivência e de respeito ao Outro tem de ser o lugar da interdisciplinaridade e da transdisciplinaridade, porque essas, "[...] ao quebrar os muros das disciplinas, formam espíritos abertos, democráticos e ensinam o respeito ao Outro" (PAVIANI, 2005, p. 120). Esse movimento contínuo de integração entre 
conhecimentos teóricos que caracteriza a transdisciplinaridade e a interdisciplinaridade não pode ser determinado a priori, não pode ser dado, deve ser definido no decorrer do processo ensino-aprendizagem, das discussões e vivências em sala de aula, dos anseios dos alunos e dos questionamentos que esses anseios provocam no espírito do professor.

Como afirma Paviani (2005, p. 122):

Diante dessa perspectiva, é secundária e, às vezes, negativa, a utilização de critérios político-administrativos para elaborar um programa de formação profissional que atenda às exigências da ciência e à consciência ética. Os verdadeiros critérios são os epistemológicos-pedagógicos, isto é, surgem do interior do processo ensino-aprendizagem.

Daí a conhecida assertiva de Warat sobre a preparação da aula. É por isso que ele afirma que a aula não pode ser algo preparado, não pode ser predeterminada. A aula preparada, mecanizada, converte-se em técnica, e é necessário conviver com o novo. Segundo esse genial pensador argentino:

Existe na articulação carnavalizada dos discursos um elemento dinâmico - e num certo sentido irracionalista - que servirá para exorcizar um dia-a-dia sem imprevisibilidade e sem espontaneidade [...]. É uma franca revolta contra o paradigma da distinção, do dever e do método, tão caracterizador das funções totalizantes das ciências sociais do nosso século, a carnavalização instaura um clima compreensivo para - lembrando algumas coisas do romantismo - recuperar a espontaneidade e neutralizar a suprema racionalidade dos quadros de referência que, antecedendo-a, amarram a vida. A cosmovisão carnavalesca abala ou enfrenta princípios, crenças ou mecanismos que colocam a razão acima da vida. (WARAT, 2000, p. 140)

É a transgressão Waratiana, enfim, que inspira o despertar de um novo limite de sentido para o ensino jurídico. E é dele o testemunho: 
Não existe distância entre linguagem e mundo. As falas sobre o mundo fazem parte do mundo. Negá-lo é ideológico. Eu pratiquei uma opção carnavalizada para o ensino do direito. Assim como os Beatles para a música inglesa. De minha parte, tento erotizar o ensino do Direito, subvertendo aos poucos algumas cabeças, instigando-as a perseguir os sinais do novo. Do meu ponto de vista, quando o homem fica sensibilizado para detectar os sinais do novo, é porque sua prática já mudou. (WARAT, 2000, p. 160)

Trata-se de um resgate da educação em sua dimensão fundamental, não como castração, mas como limite. Limite formador e limite do qual partem as possibilidades de sentido. Nunca o limite como parada. Não como ideologia, mas como autenticidade. Não como experimento, mas como experiência, em uma dimensão do novo, que pressupõe o convívio com o incerto, porque "[...] a incerteza, que mata o conhecimento simplista, é o desintoxicante do conhecimento complexo". (MORIN, 2006, p. 31)

Um novo pensar que permite compreender a educação e traçar os pontos de partida da relação professor e aluno, como afeto e responsabilidade, como saber e como sabor, como projeto que não reconhece um método único, mas também não condena de modo maniqueísta o método, reservando para o "acontecer" da aula para o rumo a ser traçado, dialogado, e não imposto. Um traçar rumos que não se compraz com o desenvolvimento de projetos de reforma do ensino baseadas em tópicos ou etapas de assimilação de reformas. Um traçar rumos que é iniciado pela compreensão do educador sobre o seu papel de responsabilidade frente a uma missão crucial para o desenvolvimento positivo da humanidade, para a sua própria sobrevivência. Um não disciplinamento, compreensão que envolve, e até mesmo exige, o reconhecimento do rosto do Outro, num encontro do homem com os homens no mundo.

Enfim, porque, como na utopia de Cornelius Castoriadis (apud DELACAMPAGNE, 2001, p. 192), "Em matéria de coerções inexoráveis, o ser humano precisa apenas de uma certa quantidade de calorias por dia e de algumas horas de sono. Quanto ao resto, tudo é possível”. 


\section{Conclusões}

O ensino jurídico se materializa, na atualidade, como um sistema de coerções obrigatórias que impõem aos seus atores a obediência a um sistema rígido de mútuas atribuições: professores ministram aulas direcionadas, alunos frequentam, são avaliados, e lhes é atribuído, ao final, um título. $\mathrm{O}$ modelo executado é fixo, linear. $\mathrm{O}$ ensino ofertado atende aos propósitos mercadológicos de quem o presta e, pretensamente, atende aos tomadores do serviço, em busca de um resultado final: a conclusão do curso.

Os rumos da própria dogmática deveriam ser tidos pelo início do trabalho do praxista, do autor jurídico, como o limite positivo de sentidos na projeção das possibilidades do Direito em uma sociedade em que o papel cimeiro foi dado ao Poder Judiciário. Todavia, a dogmática, desde a jurisprudência de conceitos e suas variantes jusnaturalistas - jurisprudência de interesses e jurisprudência de valores — tomou o lugar de um fim em si. No entanto, os próprios fins da dogmática restam comprometidos, na atualidade, em que o ensino jurídico é uma obrigação de resultado, sendo esse resultado a atribuição de um título ao aluno, ao final. Passarmos da dogmática insuficiente à epistemologia adequada, que pergunte os porquês do Direito, ou à práxis atenta aos valores e à responsabilidade que estão presentes na intersubjetividade, é impossível. Restam-nos os limites da impossibilidade de o ensino jurídico, formulado e executado sobre essas bases, seguir o caminho da transformação social.

Resulta trilhar o caminho do desvelamento necessário para projetar o novo, como já dito, nas microrrevoluções do dia a dia, trazendo à fala um ensino transgressor da disciplina, capaz de transformar o mundo, o mundo do aluno, do professor, do contexto jurídico, pouco a pouco. Um ensino presente na vida, transdisciplinar, não preso na disciplina e na insuficiência dos rumos que ela projeta, com o aprisionamento dos sentidos que o Direito pode, e deve, projetar na sociedade, a partir do pensamento e da práxis jurídicos a serem transportados para o mundo real a ser construído, por meio dos nossos alunos, no seio das escolas jurídicas, a projetar uma revolução de sentidos no próprio Poder Judiciário e na sociedade. 
Para esse desiderato, uma ruptura completa dos valores educacionais conhecidos foi proposta por Warat. Essa proposta, sob a luz da proposta heideggeriana de superação das metafísicas, em prol de sentidos que se dão no mundo, em uma retomada do mundo prático em lugar da técnica, significa trazer o desviante para o seio da aula, projetar um encontro/acontecimento de abertura de sentidos, entre o aluno e o conhecimento jurídico, propondo-lhe uma caminhada transformadora na qual o resultado final - a conclusão do curso - deixe de ser um fim em si (o que hoje indiscutivelmente é, sendo raras e honrosas as exceções) e passe a ser apenas um rito de passagem em direção a novas paisagens de uma caminhada que não cessa.

Não se transformará o mundo formando dogmáticos insuficientes. Precisamos de uma dogmática bem gestada, concebida e refletida, e também de uma epistemologia forte e presente. Todavia, nada disso, em um mundo preso na disciplina, será suficiente, por isso se propõe a transgressão waratiana, com a introdução do lúdico nas escolas jurídicas, para que o ensino jurídico, dogmática e epistemologicamente bem construído, seja também uma tarefa de prazer, de resgate da intersubjetividade, da transdisciplinaridade e da projeção de sentidos autênticos no mundo.

\section{Referências}

AGAMBEN, Giorgio. Estado de exceção. São Paulo: Boitempo, 2004. . Infância e história. Belo Horizonte: UFMG, 2005.

AGUIAR, Roberto A. R. Alteridade e rede no direito. Veredas do Direito, Belo Horizonte, v. 3, n. 6, p. 11-43, jul.-dez. 2006.

BARTHES, Roland. Aula. 12. ed. São Paulo: Cultrix, 1978. BAUMAN, Zygmunt. Modernidade líquida. Rio de Janeiro: Jorge Zahar, 2001.

. La hermenéutica y las ciências sociales. Buenos Aires: Nueva Visión, 2002. 
BOURDIEU, Pierre. O poder simbólico. Rio de Janeiro: Bertrand Brasil, 2005.

. As razões práticas: sobre a teoria da ação. São Paulo: Papirus,

1994.

DELACAMPAGNE, Christian. A Filosofia política hoje: idéias, debates, questões. Rio de Janeiro: Jorge Zahar, 2001.

FOUCAULT, Michel. Microfísica do poder. Rio de Janeiro: Graal, 2006.

. Vigiar e punir. Petrópolis: Vozes, 2000.

GADAMER, Hans-Georg. Hermenêutica em retrospectiva: Heidegger em retrospectiva. Petrópolis: Vozes, 2007.

. Hermenêutica em retrospectiva: a virada hermenêutica.

Petrópolis: Vozes, 2007.

. A razão na época da ciência. Rio de Janeiro: Tempo

Universitário, 1983.

. Subjetividade e intersubjetividade, sujeito e pessoa. In:

Hermenêutica em retrospectiva: a virada hermenêutica. Petrópolis: Vozes, 2007. (p. 9-27)

. Verdade e Método. Petrópolis: Vozes; Bragança Paulista:

Universitária São Francisco, 1997.

HEIDEGGER, Martin. Ensaios e conferências. Petrópolis: Vozes; Bragança Paulista: Universitária São Francisco, 2006a.

. La epoca de la imagen del mundo. In: . Caminos

de bosque. Madrid: Alianza, 1996. Disponível em: <http:www. heideggeriana.com.ar>. Acesso em: $1^{\circ}$ jun. 2007.

. Ser e tempo. Petrópolis: Vozes; Bragança Paulista: Universitária São Francisco, 2006b.

KANT, Immanuel. Sobre a Pedagogia. Piracicaba: UNIMEP, 2002.

MORIN, Edgar. Os sete saberes necessários à educação do futuro. São Paulo: Cortez; Brasília: UNESCO, 2006. 
PAVIANI, Jayme. Interdisciplinariedade: conceitos e distinções. Caxias do Sul: UCS; Porto Alegre: Pyr, 2005.

PÊPE, Albano Marcos Bastos; ROCHA, Leonel Severo. Genealogia da crítica jurídica: de Bachelard a Foucault. Porto Alegre: Verbo Jurídico, 2007.

SILVA, Ovídio A Baptista da. Processo e ideologia. Rio de Janeiro: Forense, 2004.

SOUZA, Ricardo Timm. Alteridade \& pós-modernidade: sobre os difíceis termos de uma questão fundamental. In: . Sentido e alteridade: dez ensaios sobre o pensamento do Emmanuel Levinas. Porto Alegre: PUCRS, 2000.

STEIN, Ernildo. Compreensão e finitude. Ijuí: Unijuí, 2001.

VATTIMO, Gianni. O Fim da modernidade: nihilismo e hermenêutica na cultura pós-moderna. São Paulo: Martins Fontes, 2002.

WALLAERSTEIN, Immanuel. O fim do mundo como o conhecemos. Rio de Janeiro: Revan, 2002.

WARAT, Luís Alberto. A ciência jurídica e seus dois maridos. Santa Cruz do Sul: UNISC, 2000.

. O outro lado da dogmática jurídica. In: ROCHA, Leonel Severo (Org.) Teoria do Estado e do Direito. Porto Alegre: Sergio Antônio Fabris, 1994. (p. 81-95)

Fabris, 1995.

. Introdução Geral do Direito II. Porto Alegre: Sergio Antonio

Albano Marcos Bastos Pêpe é Doutor em Direito pela Universidade Federal do Paraná (UFPR), Mestre em Filosofia pela Universidade Federal de Santa Maria (UFSM) e Graduado em Filosofia pela Universidade Católica de Pernambuco (UNICAP). Professor da Universidade do Vale do Rio dos Sinos (UNISINOS). E-mail: pepeamb@uol.com.br. 
Endereço profissional: Gabinete acadêmico. Rua da Emancipação, 52. CEP: 97.185-000. Centro, Itaara/RS.

Daniela Boito Maurmann Hidalgo é Mestre em Direito Público pela Universidade do Vale do Rio Dos Sinos (UNISINOS) e Especialista em Direito Processual Civil pela Pontifícia Universidade Católica do Rio Grande do Sul (PUC-RS). Professora Universitária nas áreas de Teoria do Direito, Filosofia do Direito e Direito Material e Processual Civil, ligada a várias instituições de ensino superior. Defensora Pública do Estado do Rio Grande do Sul. E-mail: daniela.hidalgo@ terra.com.br.

Endereço profissional: Defensoria Pública do Estado do Rio Grande do Sul. Rua Márcio Veras Vidor, 10, sala 319, CEP: 90.110-161. Praia de Belas, Porto Alegre/ RS. 